\title{
Improving Education in Neuromuscular Medicine-The Essential Ingredients
}

\author{
Dianna Quan, MD \\ Neuromuscular Medicine Fellowship, University of Colorado Denver, Aurora, Colorado, US
}

DOI: http://doi.org/10.17925/USN.2016.12.01.27

\begin{abstract}
Neuromuscular medicine fellowship training, like neurology training, is undergoing important changes. The widespread effort to standardize educational practices and assessment methods across programs is exemplified by the Next Accreditation System. The lasting effects of this framework are largely unknown and will require study. In order truly to meet the goals of improving patient and population outcomes and improving the educational experience for trainees, more changes will likely be needed.
\end{abstract}

\section{Keywords}

Neuromuscular medicine fellowship training, education, assessment, Next Accreditation System

Disclosure: Dianna Quan has nothing to declare in relation to this article. No funding was received for the publication of this article. This article is a short opinion piece and has not been submitted to external peer reviewers.

Open Access: This article is published under the Creative Commons Attribution Noncommercial License, which permits any noncommercial use, distribution, adaptation, and reproduction provided the original author(s) and source are given appropriate credit.

Received: January 17, 2016 Published: February 26, 2016 Citation: US Neurology, 2016;12(1):27-8

Correspondence: Dianna Quan, MD, University of Colorado Denver, 12631 East 17th Avenue, Mail Stop B-185, Aurora, CO 80045, US. E: dianna.quan@ucdenver.edu

In my avocation as a home cook, I found interesting a passage in Fuchsia Dunlop's Shark's Fins and Sichuan Pepper, a memoir of the author's culinary journey in China. ${ }^{1}$ She describes an elderly gourmet's lament for the rising dominance of culinary school education over traditional chefs' apprenticeships. He was dismayed by the substitution of mass-produced cooks, armed with standardized repertoires and knowledge, for highly skilled chefs with both a solid foundation in traditional techniques and the ability to innovate with new methods.

This evolution in the educational system of professional chefs in China echoes the changes we have seen in numerous American professions in the last several decades, including medicine, neurology, and neuromuscular medicine. Some of the most visionary physicians in neuromuscular medicine today are graduates of an apprenticeship system, and learned at the side of masters who defined our field. As recently as 10 years ago, most neuromuscular physicians trained in such unregulated programs, many with decades-long traditions of educational excellence. Some still do. The system worked but produced trainees with variable levels of competence, and no yardstick existed to compare graduates across programs.

A decade ago, the Accreditation Council for Graduate Medical Education (ACGME) - whose mission is to "improve health care and population health by assessing and advancing the quality of resident physicians' education through accreditation" - put forth a set of requirements for neuromuscular medicine that mirrored the existing framework for neurology and physical medicine and rehabilitation residencies. ${ }^{2,3}$ The fundamental skills expected of a neuromuscular specialist were detailed in these program requirements, accompanied by mandated didactic topics and clinical experiences, supervisory requirements, duty hour restrictions, and alertness management/fatigue mitigation training requirements, among other matters. This effort to standardize the knowledge base, educational process, and skills of neuromuscular practitioners has necessitated the tandem development of assessment methods and tracking measures to ensure that programs and physicians are up to par. The latest iteration prescribed by the Next Accreditation System (NAS) includes 17 pages of milestones and two faculty meetings per year to review the status of trainees. ${ }^{4,5}$ ACGME accreditation specifies the minimum level of infrastructure and support required for educational programs, and subspecialty certification endorses that graduates of such programs have achieved competency by passing a detailed written examination.

Do reducing variability in educational practices across programs, tracking program and trainee adherence to guidelines, and frequent assessments enhance physician competency, improve patient outcomes, and reduce costs through efficient use of resources? Do these measures improve individual health and population health? The answers are by no means clear, and more research is needed to address these questions.

Mastery of a common body of knowledge is essential and provides the vocabulary and foundation for future practice. Gauging this is the main utility of a certification examination. Do all trainees require formal didactic lessons to acquire this knowledge? For programs with one or two fellows, is the annual repetition of formal, didactic lessons an efficient use of teaching resources? If mastery over a core curriculum is the desired outcome, then there should be a standardized core curriculum, using written syllabi, electronic resources, and virtual classrooms to teach it. Those who 
teach in the virtual classroom should be the best within our subspecialty, and the content should be managed to allow for the dissemination of the most up-to-date material. All trainees should have the opportunity to partake. For small subspecialties such as neuromuscular medicine (which currently has 45 accredited programs nationally, many of which have only one or two filled positions), a shared effort would be superior to the local processes that are currently variably replicated in every program across the country. This effort would require a high level of cooperation and teamwork among programs and a willingness to reorganize our educational processes in a very fundamental way. Some might fear that a universal didactic curriculum would not maximize individual learning or that the burden and cost of developing such a high-level program would be disproportionately distributed. There might be concerns that fellows would not have the discipline or time to independently access these resources or that they would not be sufficiently interactive to promote learning. More parochially, there might be concerns that such a program would dilute the appeal of some of the traditionally strong fellowships that are known for their outstanding faculties. Numerous other concerns and challenges would surface, which were all valid and important, but surmountable. Nor would there ever be a substitute for the intimacy of local didactic courses to supplement core resources based on individual trainee needs.

Fellowships are the time for fine-tuning a physician's skills and knowledge. The local apprenticeship factor is the essential ingredient in a complex educational process, and it is the quality and outcome of this interaction that ultimately determines how well prepared a fellow is to become a fullfledged member of our subspecialty. Variability is inevitable and desirable in order to facilitate individual learning and patient care. The shared qualities of good apprenticeships can be described, but their methods are difficult to dictate. Still, these methods will always distinguish our best fellowship programs and practitioners. One day we may find assessment tools to determine what works best to raise our specialty as a whole to its highest level of excellence, but we are not there yet.

1. Dunlop F, Shark's Fins and Sichuan Pepper: A sweet-sour memoir of eating in China, New York: WW Norton \& Company, 2008;80.

2. About ACGME, 2016. Available at: www.acgme.org/acgmeweb/tabid/116/About.aspx (accessed January 16, 2016).

3. ACGME Program Requirements for Graduate Medical Education in Neuromuscular Medicine, 2015. Available at: www.acgme.org/acgmeweb/Portals/0/PFAssets/ProgramRequirements/183-343_neuromuscular_ med_07012015_1-YR.pdf (accessed January 16, 2016).

4. Nasca TJ, Philibert I, Brigham T, Flynn TC, The Next GME Accreditation System — Rationale and Benefits, N Engl J Med, 2012;366:1051-6.

5. The Neuromuscular Medicine Milestone Project, 2015. Available at: www.acgme.org/acgmeweb/Portals/O/PDFs/Milestones/NeuromuscularMedicineMilestones.pdf (accessed January 16, 2016). 